\title{
PSYCHE
}

\begin{tabular}{lll}
\hline Vol. 88 & 1981 & No. 3-4 \\
\hline
\end{tabular}

\section{SOUND PRODUCTION BY COURTING MALES OF PHIDIPPUS MYSTACEUS (ARANEAE: SALTICIDAE) ${ }^{1}$}

\author{
BY G. B. EDWARDs ${ }^{2}$
}

The courtship rituals of male salticids generally are considered to be visually-oriented, despite the fact that a primarily tactile type of courtship has been demonstrated for 2 species of Phidippus (Edwards, 1975; Jackson, 1977). In addition, chemotactic cues probably assist a male in locating a female in most species of jumping spiders (Crane, 1949; Richman, 1977). I report here that males of Phidippus mystaceus (Hentz) produce sound by means of a palpal stridulatory mechanism as an integral part of their courtship. This is the first known case of a salticid producing sound with this type of mechanism; a similar stridulatory organ has been reported for lycosid spiders (Rovner, 1975).

Petrunkevitch (1926) reported that the salticid Stridulattus stridulans Petrunkevitch has a stridulatory organ (of type "d", chelicerapalpus; Legendre, 1963). However, he did not detect sound production. The only other records of a salticid producing sound were by Bristowe (1958), who reported that Euophrys frontalis (Walckenaer) made a "distinct sound as the tarsal claws (of the legs I of the male) hit the ground ...." and by Bristowe and Locket (1926), who had reported earlier on the same species, but had implicated the legs II as the sound producers. In either case, it was not clear if the sound produced by $E$. frontalis was an integral part of the courtship or incidentally produced by the movement of the legs.

\footnotetext{
'Contribution No. 514, Bureau of Entomology, Division of Plant Industry, Florida Department of Agriculture and Consumer Services, Gainesville, FL 32602.

${ }^{2}$ Florida State Collection of Arthropods, Division of Plant Industry, P. O. Box 1269, Gainesville, FL 32602.

Manuscript received by the editor June 7, 1981.
} 


\section{Experimental Procedure}

Four females and 2 males of $P$. mystaceus were reared to maturity from an eggsac containing 12 eggs. ${ }^{3}$ The spiders were housed separately in $9 \times 1 \mathrm{~cm}$ plastic petri dishes; twice a week they were provided with water by moistening a wad of cotton within the dish and were fed larvae of the cabbage looper, Trichoplusia ni (Hübner).

Two different techniques were used for observing courtship. In one method, the male was placed directly into a female's petri dish, on the side opposite the female. In the other method, the male and female were placed $5-15 \mathrm{~cm}$ apart on a $30 \times 10 \mathrm{~cm}$ section of a liveoak branch, in order to simulate natural conditions. Temperature ranged from $24-26^{\circ} \mathrm{C}$ for all sessions.

Six separate filming and/or recording sessions lasted 10-90 min. each. Films were made using a Beaulieu Super-8-mm movie camera and an Auricon Pro 600 16-mm movie camera. Sound recordings were made with a Sony TC-756-2 reel-to-reel tape recorder and a Turner S22D microphone. The audiospectrogram was produced on a Kay 7029A Sound Spectrograph.

\section{RESULTS}

Courtships were observed for one of the males (the second male was killed by the first female with which he was placed). Typically a male placed into the petri dish housing a female almost immediately begins palpating the female's draglines and her abandoned nests, continuing this palpal exploration until he detects the female visually.

If the female is not inside a nest when first seen by the male (usually from 3-6 cm), the male begins producing a soft, audible trill that is systematically repeated. By apparently engaging the substrate with enlarged setae (macrosetae, Fig. 1; similar to those observed on lycosids by Rovner, 1975), leverage is produced enabling a stridulatory mechanism on the palpus to be operated. This mechanism consists of a plectrum-like projection of the tibial apophysis which fits into a bowl-shaped area on the cymbium containing a complicated file system. The entire mechanism is located laterally (ectally); in lycosids it is located dorsally. Also, lycosids have the file on the

${ }^{3}$ Gravid female $P$. mystaceus collected by Robert Dye, 26 October 1975, 4 miles north of Texas state line at a rest stop on I-35 in Oklahoma, under a rock. Eggs were laid November, 1975. 
tibia facing a cymbial plectrum, the reverse of the condition in $P$. mystaceus. The file system of $P$. mystaceus appears to consist of 2 types of adjacent file fields which blend into one another. Within the concavity is a fan-shaped file, while along the distal edge of the concavity is a linearly-arranged file similar to lycosid files. Neither file is as well-defined as the lycosid files. The individual ridges of $P$. mystaceus' files are rounded, whereas those of lycosids have distinct edges; however, in P. mystaceus, both types of file are overlaid with numerous short ridges of variable length (Fig. 2).

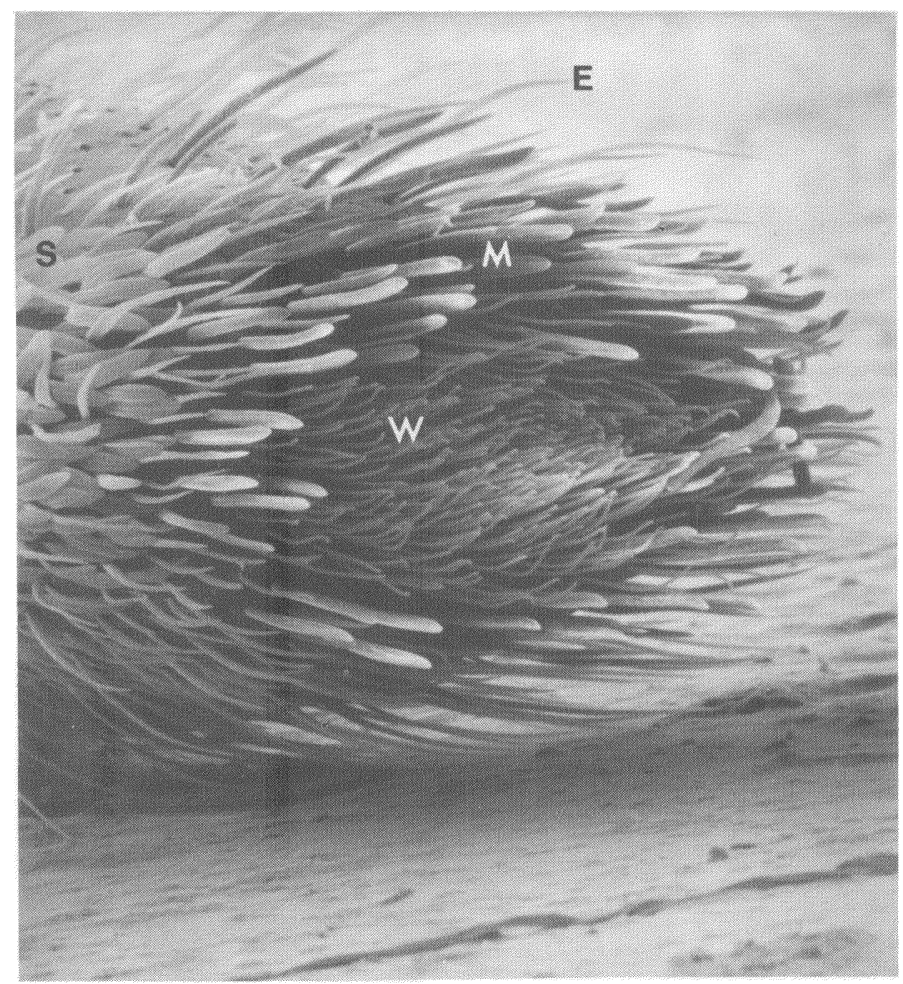

Fig. 1. Distal tip of palpus of male P. mystaceus showing ring of macrosetae (M) encircling whorled chemotactile setae (W). On extreme left are scale-like setae (S) which form part of a white and/or yellow spot which probably contributes to the overall visual stimulus of a courting male $(100 \mathrm{X})$. Note the greater number of macrosetae on the ectal edge (E); see text for explanation. The curved macrosetae (extreme right) at the tip of the cymbium first contact the substrate and may facilitate the backwards sliding motion of the palpi by reducing friction with the substrate. 

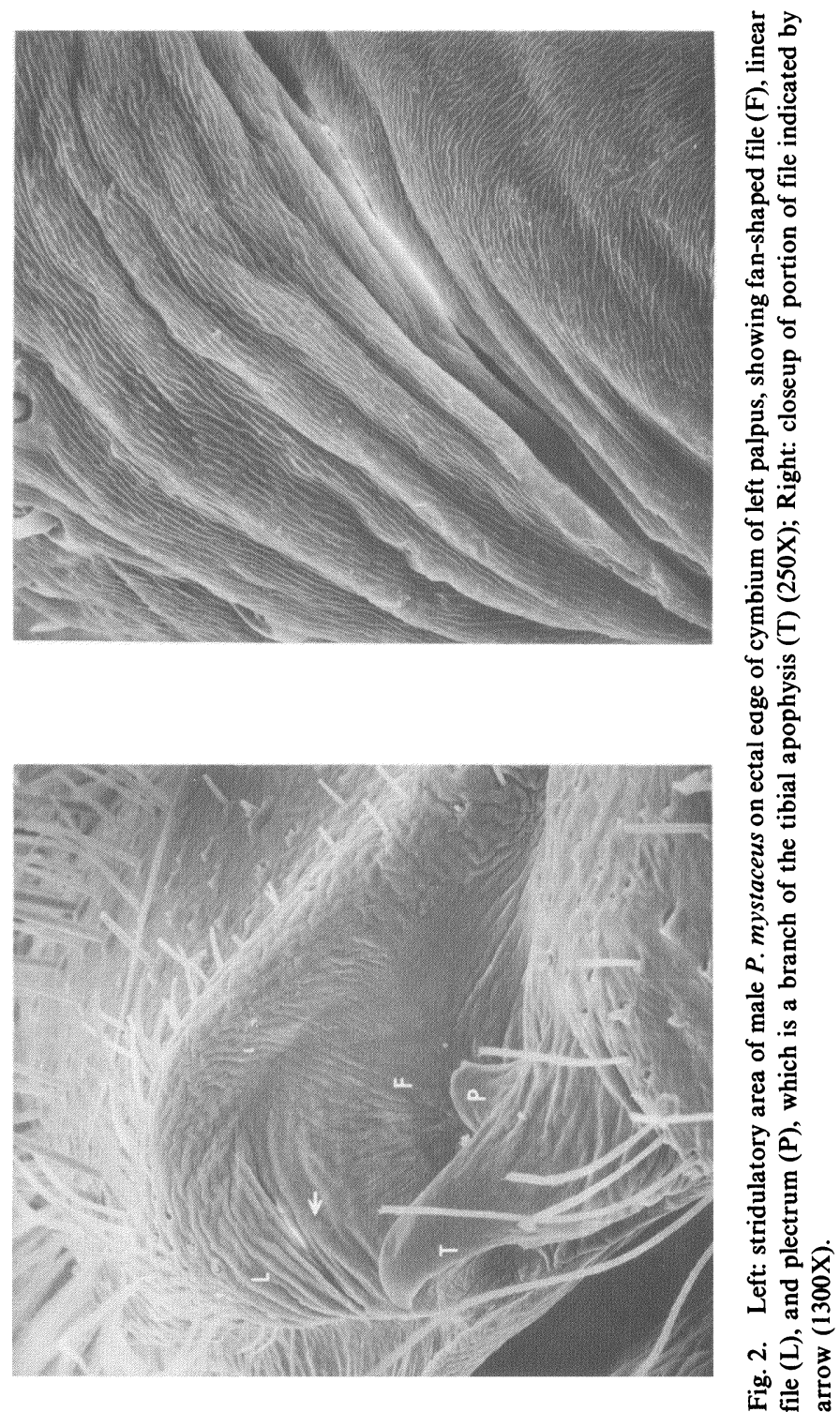

这运 
For each sound sequence, both palpi become engaged nearly simultaneously by a backward movement in which the palpi appear to be dragged along the surface of the substrate for a distance of about $1 \mathrm{~mm}$. Halfway through the backward movement, the cymbia are bent backward at an angle to the palpal tibiae (Fig. 3). At the end of the backward movement, the palpi remain stationary for a fraction of a second while the cymbia are rotated outward (left palpus clockwise, right palpus counter clockwise). The palpi are then returned to their most anterior position, apparently by lifting the palpi from the substrate and moving them forward. When the palpi are in their most anterior position, they are clearly off the substrate. A single cycle of palpal movement is approximately 0.8 second ( 5 frames at 6 frames per second).

Audiospectrograms indicate that $13-20(\overline{\mathrm{x}}=17, \mathrm{n}=8)$ paired stridulations are made consecutively, separated by pauses subequal in timing to the sound sequences (Fig. 4). Alternation of stridulations and pauses occurs at the rate of 1.5 sound sequences per second (at approximately $25^{\circ} \mathrm{C}$ ).

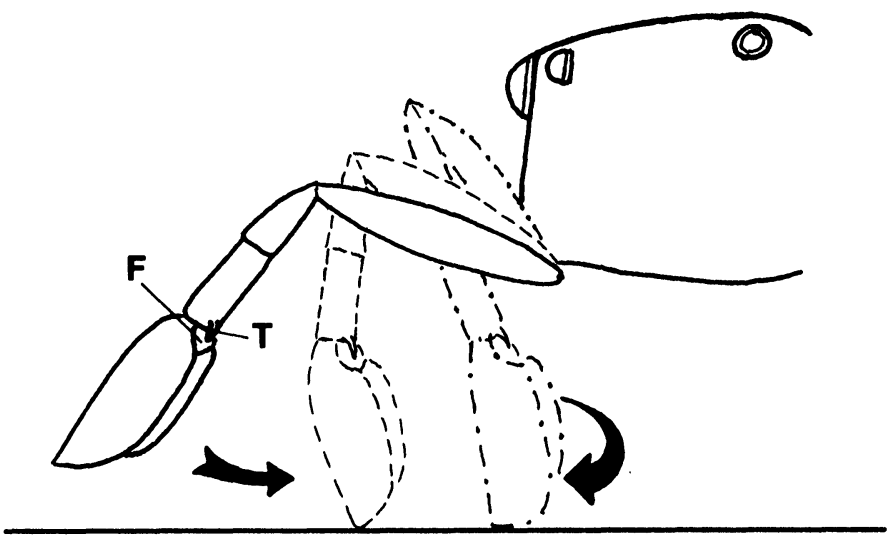

A

B

C

Fig. 3. Diagrammatic illustration of movement of left palpus (ectal view) by male $P$. mystaceus during stridulation. A. Anterior position. B. Backward movement, during which cymbium is bent backward, moving fan-shaped file across plectrum. C. Rotary movement, during which macrosetae are engaged in substrate and cymbium is rotated outward, moving linear file across plectrum. $\mathrm{F}=$ File cavity, $\mathrm{T}=$ Tibial apophysis. 
Simultaneous with the initiation of sound production, the male extends his legs I forward, positioning them just above and parallel to the substrate, and spread approximately $40^{\circ}$ apart. The tarsi and metatarsi are turned upward about $15^{\circ}$ and occasionally flicked upward together. On 1 occasion, at a distance of about $1 \mathrm{~cm}$ from the female, the tarsi and metatarsi were flicked continuously for several seconds at approximately 2 flicks per second.

The male's approach usually is direct, without the zigzag movement (lateral stepping movement) characteristic of some other Phidippus species and many other salticids. Forward movement is slow and halting, the male often remaining in one spot for several minutes. Total courtship time is long compared to the rapid advance of the males of some Phidippus species, on 3 occasions lasting approximately 8 minutes before the female terminated the courtship by leaving the vicinity. These 3 longest courtships reached an advanced stage, wherein the male brought his legs I closer together, touched the female, and attempted to mount her; however, none of the 4 females allowed their male sibling to mate with them. Instead, each raised her legs I to repel him, and, if the male was persistent, lunged sharply forward with open fangs, struck downward with the legs I, and forced him backward; the female then left the vicinity.

On 2 occasions, the male performed a zigzag display; once prior to assuming his stridulatory stance, and once in the middle of courtship after several sequences of stridulation. In the first instance, the zigzag display was brief, lasting less than 30 seconds and consisting of 4 changes of direction, with a pause between each lateral move. In the second instance, during mid-courtship, 7 multiple zigzags occurred which included 1-3 changes of direction during each lateral stepping sequence; total elapsed time was about 3 minutes.

If the female is initially in and remains in a nest when the male is introduced into the petri dish, the male alternates palpation of the substrate with sequences of stridulation. Upon finding the nest sheltering the female, the male attempts to gain entrance by probing and pulling at the silk with his legs I, interspersing sequences of palpal vibration on the silk. (Note: other species of Phidippus known to use a tactile courtship vibrate their entire body). I could not determine the movement pattern of this palpal vibration (it 


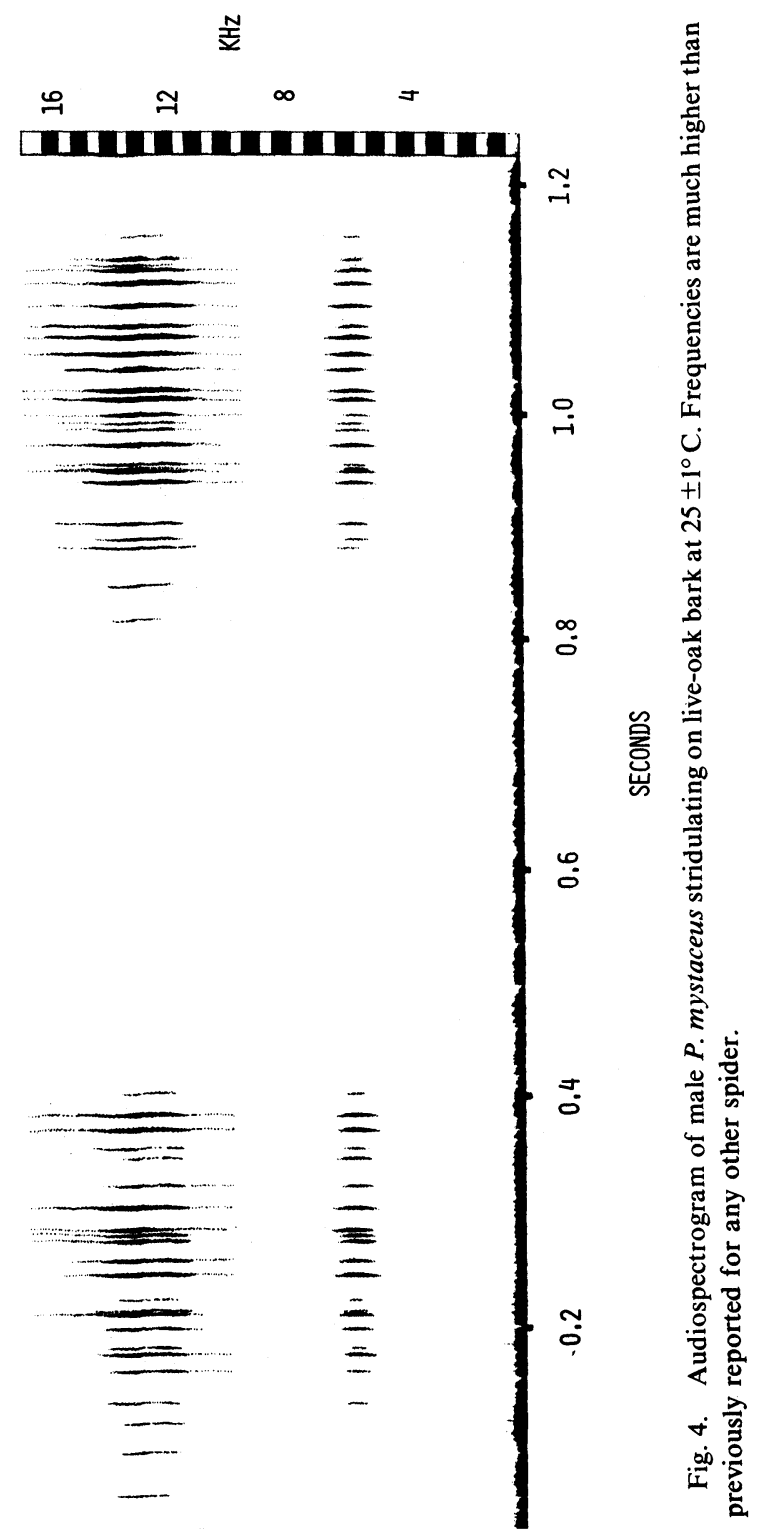


appeared to be similar in timing to stridulation), but the palpi were not in contact with the petri dish, and no audible sound was produced.

\section{Discussion}

Known reproductive behavior of the males of species of Phidippus involves a male locating a female by visual or chemotactic means (Richman, in press), a visually-oriented courtship by the male consisting of a series of movements with the legs I and palpi (usually while advancing in a zigzag path), mounting of the female by the male, and mating. Typically the male is conspicuously marked with bright and/or contrasting colors both anteriorly and dorsally; the anterior patterns are displayed during courtship. Unlike most other species, both males and females of P. mystaceus are cryptically-colored gray spiders that live in trees (Specht and Dondale, 1960; Warren et al., 1967, as P. incertus; see Edwards, 1977 , for nomenclatorial comments); males have mostly anteriorlyoriented modifications (Fig. 5). While anterior modifications are probably used by each sex to identify the other (especially the female recognizing the male as a conspecific and potential mate) from distances of a few centimeters, visual identification at longer distances might be severely handicapped by cryptic coloration. A mechanism which increases the chance of one sex locating the other could be selected for under these circumstances.

The role of acoustic or vibratory signals in the courtship of $P$. mystaceus may have co-evolved with cryptic coloration. As selection for cryptic coloration increased in association with exploitation of a new microhabitat (most Phidippus species live in the herbshrub zone), the role of visual communication might have been in part supplanted by sound during courtship. The use of sound, whether airborne or substrate-borne, would have several advantages over conventional visual courtship, if the sound extended the male's communicatory distance from a few centimeters to over a meter (as it appears to do based on the audible component available to the human ear). Sound is transmitted well through solids, and considering that in this case sound is produced on the substrate, vibrations through this medium may be most important for female-to-male orientation (as Rovner, 1967, showed to be the case for wolf spiders). By orienting toward the male upon perception of the 

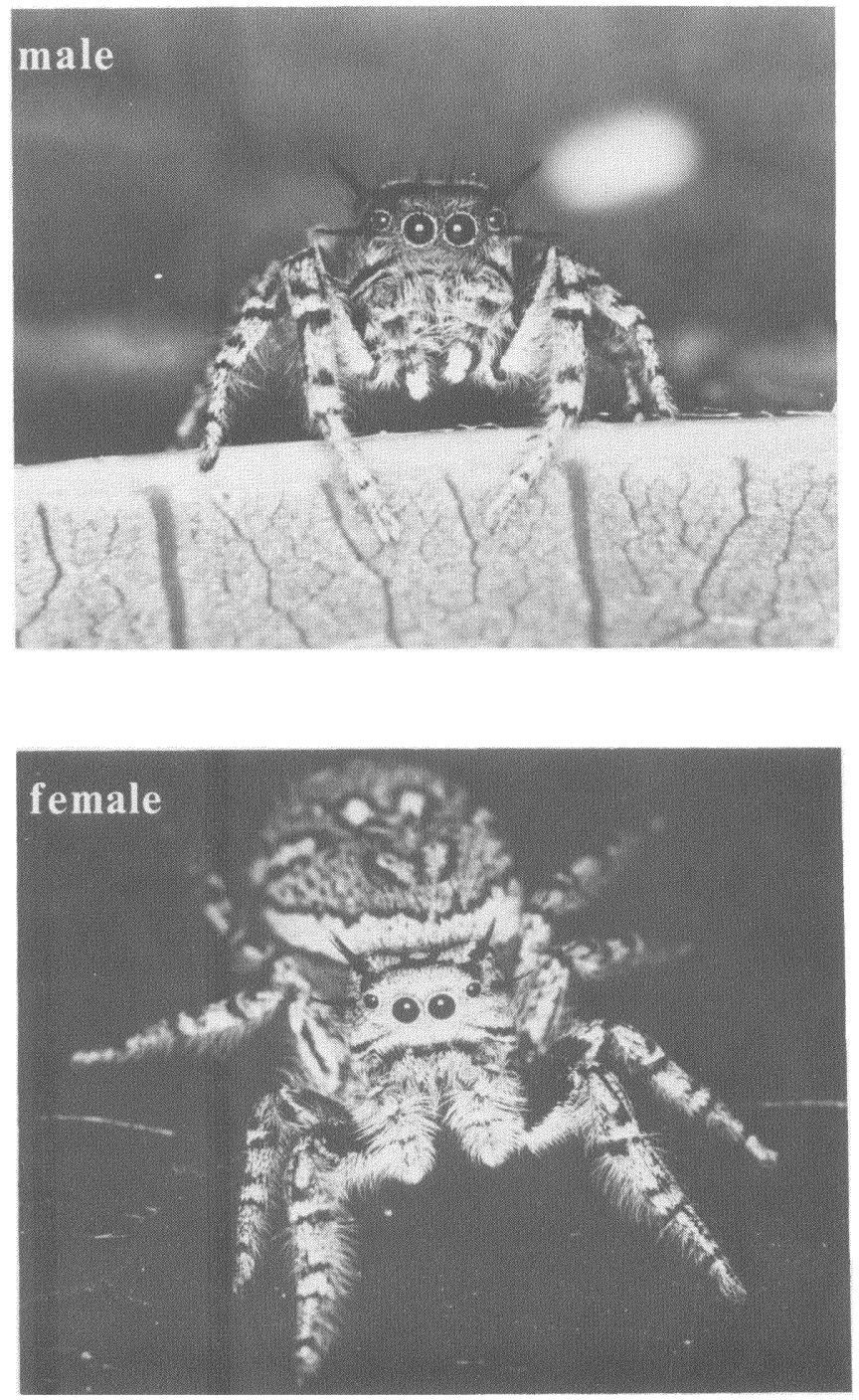

Fig. 5. Anterior views of male and female $P$. mystaceus, offspring of female collected in Oklahoma, which were used in this experiment. 
sound, the female might sooner visually detect and be able to evaluate the male as a prospective mate, and thus sooner choose to wait for or flee from him. The advantages gained by the male by increasing his communicatory distance might be: 1) alerting a receptive female to his presence at a greater distance, possibly causing her to remain in the vicinity for a longer period of time (and perhaps inhibiting her predatory instincts), so that the male has a greater chance of finding and courting her; 2) based on many observations of $P$. mystaceus and of other Phidippus species, nonreceptive females usually avoid advancing males; thus, by alerting a female to his presence at a greater distance, a male would reduce the chance of stimulating an aggressive response by a non-receptive female.

As evidence for these probable advantages, analysis of courtships showed that the male began courting a female from 2-4 times further away when unconfined (on the live-oak branch) than did other species of Phidippus when observed under unconfined experimental conditions (Edwards, 1975). At the greater distances, only sound was used initially by a $P$. mystaceus male upon sighting a female, indicating that this form of communication was important in alerting a female to his presence. Sound was also used alternately with palpal exploration of the silk when the male was in contact with the female's draglines in the petri dish, even though she was not visible. Under natural conditions, a male likely would often encounter a female's dragline prior to locating her; he could maximize his chances of mating by beginning to signal immediately, regardless of whether or not the female was visible to him.

\section{Components of Behavior and Morphology}

The male's initial palpal exploration of the female's silk draglines and nests has been noted for other salticids (Richman, 1977). The presence of a contact pheromone on the silk could indicate to a male that a female was, or had been, in the vicinity. Contact pheromones (Hegdekar and Dondale, 1969) and dragline following by males (Tietjen and Rovner, 1980) have been demonstrated for some lycosids, but have not yet been conclusively demonstrated for any salticid. Foelix (1970) demonstrated the presence of chemosensitive setae in certain araneid spiders and hypothesized that those setae were contact chemoreceptors. He showed that the suspected chemo- 
sensitive setae in araneids were innervated and structured in essentially the same manner as pheromone receptors of insects. Hill $(1977 \mathrm{a}, \mathrm{b})$ noted that the whorled setae on the tarsi and palpal cymbia of several species of Phidippus also resembled insect pheromone receptors; male $P$. mystaceus have the same type of setae on their palpal cymbia (Fig. 1).

The behavior in $P$. mystaceus of engaging the palpi against the substrate is probably derived from similar behavior among its relatives. Males of other species of Phidippus move their palpi up and down or back and forth during courtship. This behavior appears to pre-adapt them for engaging the substrate, since only a slight change in the amplitude and/or attitude of these movements would bring the palpi into contact with the substrate. The same movement occurs more intensely and rapidly when a male encounters silk made by a female, in association with presumed chemotactile exploration; it is likely that this is the evolutionary pathway of the development of the use of sound in P. mystaceus.

The shape and arrangement of the macrosetae at the tip of the cymbium are such that a downward, forward pressure would engage them with the substrate. By dragging the palpus backward, enough leverage apparently is produced to move the fan-shaped file across the relatively stationary plectrum; however, the backward movement and bend of the palpus also may be a prerequisite to positioning the macrosetae onto the substrate. Once the palpus is anchored onto the substrate, the cymbium is rotated laterally outward, then the palpi are returned to their starting position. The macrosetae are arranged in a circle around the tip of the cymbia in $P$. mystaceus, with more macrosetae on the ectal edge than on the ental edge, which enables the palpus to remain engaged with the substrate as it rotates outward. The structure involved in sound production by rotating is the linear file; the cymbium must be rotated sideways due to the lateral position of the file.

By simulating the direction of palpal movement with a model, it is apparent that the backward movement would cause the fan-shaped file to be drawn across the plectrum, while the rotary movement would bring the linear file into contact with the plectrum. The fan shape of the proximal file would accommodate the arc-shaped movement as the palpus is bent on the backward stroke; however, sound does not seem to be produced by the fan-shaped file. Only 
one type of stridulation is produced, evidently from the linear file (see figure 4); the function of the fan-shaped file remains unclear. Although the files appear to be oriented so that they could be stroked from either direction, the timing of a complete palpal movement indicates that sound is produced only on the backstroke and not on the return stroke. The mechanics of stridulation by $P$. mystaceus are still incompletely understood, and need further study with more sophisticated filming techniques.

\section{Comparisons to Other Stridulatory Mechanisms}

The behavioral application of the palpi to the substrate by $P$. mystaceus differs from lycosids in that $P$. mystaceus moves the tips of the palpi while stridulating during each brief sound sequence, whereas the lycosids apparently remain attached in one place to the substrate for a prolonged sequence of sound production. The mechanics of sound production with the linear file are similar to those of the lycosids with respect to the palpus anchored by macrosetae and the similar file structure, but $P$. mystaceus differs from the lycosids in the location of the stridulatory organ, the type of movement needed to engage the file, and the reversed positions of the file and plectrum. Rovner (1975) proposed a new category of stridulatory organ (as an extension of the classification of Legendre, 1963), type " $h$ " to accommodate those types of mechanisms in which the file and plectrum (scraper) were on adjacent surfaces of a joint within the same appendage. I propose a subdivision of Rovner's category, following Legendre's method of subdividing categories: type " $\mathrm{h}$ " in which the file is on the more proximal segment (as in lycosids), and type "h II" in which the file is on the more distal segment (as in P. mystaceus).

The stridulatory mechanisms known in other spiders incorporate plectrum and file systems on opposing faces of the chelicerae and palpi, legs I and II, carapace and legs I, carapace and abdomen (Gertsch, 1979), or between palpal tibia and tarsus (Rovner, 1975). In each of these cases, either the plectrum is moved across a stationary file or both plectrum and file are moved together. The stridulatory mechanism of $P$. mystaceus differs from all of these in that the primary moving part is the file. Although the plectrum is passively moved in space during the movement of the palpus to 
engage the substrate, the cymbium containing the files is actively moved against the plectrum on the tibia. When the palpus is fixed on the substrate with the macrosetae, again it is the cymbium that is moved against the stationary plectrum.

\section{Other TyPes of Vibratory Signaling}

A third method of sound production in spiders, vibration (producing a "buzz" similar to that of a fly), has been demonstrated for the sparassid spider, Heteropoda venatoria (L.) (Rovner, 1980). In the same paper, low amplitude appendage oscillations resulting in a faint whirring sound were reported for Lycosa rabida Walckenaer. Phidippus whitmani Peckham and Peckham employs entire-body (?) vibration (lacking an audible component, but with a widelyspaced stance similar to $H$. venatoria) during its Type I visual courtship (Edwards, 1980). This is probably an adaptation to its microhabitat (mesophytic leaf litter), the same substrate used for vibratory signaling by many lycosids. I have noted another vibratory behavior that also seems similar to that of $H$. venatoria during the Type II tactile courtship of Phidippus regius $\mathrm{C}$. L. Koch, while the male is contacting the nest of the female (Edwards, 1975). Subsequent laboratory observation showed a similar behavior for $P$. whitmani; although the timing of vibratory sequences was different from those of $P$. regius, probably a species-specific difference. Jackson (1977) reported a similar behavior for P. johnsoni (Peckham and Peckham) and suggested a similarity in some respects to the vibratory courtships of web-building spiders. I suspect that the vibratory courtships of Phidippus species, although not producing an audible component that I could detect, may be more like the courtship of $H$. venatoria than like web-builders, or perhaps all 3 groups produce vibrations in essentially the same way (i.e., "juddering" as in araneid males; Robinson and Robinson, 1980). It is curious that all known forms of non-tactile direct inter-individual communication not involving vision in salticids are acoustic or vibratory signals (despite the contention of Crane, 1949, and other authors, the use of airborne pheromones by salticids has never been proven). In the case of $P$. mystaceus and $P$. whitmani, both visual and vibratory signals are used simultaneously, although the 2 species produce vibrations in different ways. 


\section{Conclusion}

The use of stridulation to produce sound by $P$. mystaceus appears to represent a third method of communication for salticids (a fourth method, if the tarsal percussion of Euophrys frontalis is a valid communicatory process). Despite the fact that females used for the present research failed to respond favorably to courtship by their sibling male, the behavioral and morphological evidence in the male of a functional role for sound production during courtship is substantial. ${ }^{4}$

\section{SUMMARY}

Males of Phidippus mystaceus have a stridulatory organ located on the tarsal and tibial segments of the palpi. This organ is employed by males in the potential or actual presence of adult females, and forms the most significant part of courtship by males. The mechanics of stridulation are somewhat similar to those of lycosids, and as with the lycosids, substrate vibrations may be the most important component of stridulation. Evolution of sound production by $P$. mystaceus is hypothesized to have occurred in conjunction with the evolution of cryptic coloration. Sound production is thought to extend the males' communicatory distance, compensating for fewer visual identification opportunities due to the spiders' cryptic coloration.

\section{ACKNOWLEDGMENTS}

I would like to give special thanks to the following: Dr. Robert Paul for his help in sound recording and producing the audiospectrogram; Dr. Jonathan Reiskind for the S. E. M. photomicrographs. Thanks are also due; Mr. John Thorne and Mr. Stan Blomely for

${ }^{4}$ Two antepenultimate $P$. mystaceus were collected by G. B. Edwards, 28 July 1979, Ocala National Forest, Marion Co., Florida, beating young scrub live oaks, and reared to maturity (October, 1979). Although these specimens were collected and reared after the research on the Oklahoma specimens was completed, and the courtship was neither filmed nor recorded, a courtship and mating was observed for this pair. Courtship appeared in all respects to be identical to that of the Oklahoma male, including type of sound, stance, and the rapid upward flicking of the tarsi and metatarsi at less than $1 \mathrm{~cm}$ distance from the female. Mating occurred in the female's nest and lasted 87 minutes until the female left the nest. Upon separating, the male renewed courtship, initially showing a single lateral stepping sequence as in the Oklahoma male. The female avoided the male, and the pair was separated. 
aid in filming (16-mm); Mr. Lloyd R. Davis, Jr., for obtaining the gravid $P$. mystaceus female for me; and Drs. Jerome S. Rovner, Jonathan Reiskind, Thomas J. Walker, and Robert L. Crocker for reviewing the manuscript.

\section{Literature Cited}

Bristowe, W. S.

1958. The World of Spiders. Collins, London. $305 \mathrm{p}$.

Bristowe, W. S., AND G. H. Locket.

1926. The courtship of British lycosid spiders, and its probable significance. Proc. Zool. Soc. London 1926(2): 317-347.

Crane, J.

1949. Comparative biology of salticid spiders at Rancho Grande, Venezuela. Part IV. An analysis of display. Zoologica 34(4): 159-215.

EDWARDS, G. B.

1975. Biological studies on the jumping spider, Phidippus regius C. L. Koch. M.S. Thesis, University of Florida. $64 \mathrm{p}$.

1977. Comments on some genus and species problems in the Salticidae, including Walckenaerian names. Peckhamia 1(2): 21-23.

1980. Taxonomy, ethology, and ecology of Phidippus (Araneae: Salticidae) in eastern North America. Ph.D. Dissertation, University of Florida. 354 p.

Foelix, R. F.

1970. Chemosensitive hairs in spiders. J. Morphol. 132: 314-334.

GerTSCH, W. J.

1979. American Spiders. Van Nostrand Reinhold Co., Second Edition, New York. 274 p.

Hegdekar, B. M., and C. D. Dondale.

1969. A contact sex pheromone and some response parameters in lycosid spiders. Canad. J. Zool. 47(1): 1-4.

HiLl, D. E.

1977a. The pretarsus of salticid spiders. Zool. J. Linnean Soc. London 60(4): 319-338.

1977b. Modified setae of the salticid pedipalp. Peckhamia 1(1): 7-8.

JACKSON, R. R.

1977. Courtship versatility in the jumping spider, Phidippus johnsoni (Araneae: Salticidae). Anim. Behav. 25(4): 953-957.

LEGENDRE, R.

1963. L'audition et l'émission de sons chez les aranéides. Ann. Biol. 2: 371-390.

Petrunkevitch, A.

1926. Spiders of the Virgin Islands. Trans. Connecticut Acad. Arts Sci. 28: 21-78.

RichMAN, D. B.

1977. The relationship of epigamic display to the systematics of jumping spiders (Araneae: Salticidae). Ph.D. Dissertation, University of Florida. $162 \mathrm{p}$. 
1982. Epigamic display in jumping spiders (Araneae: Salticidae) and its use in systematics. J. Arachnol. 10 (in press).

Robinson, M. H., and Barbara Robinson.

1980. Comparative studies of the courtship and mating behavior of tropical araneid spiders. Pacific Insects Monograph 36: 1-218.

ROVNER, J. S.

1967. Acoustic communication in a lycosid spider (Lycosa rabida Walckenaer). Anim. Behav. 15: 273-281.

1975. Sound production by Nearctic wolf spiders: A substratum-coupled stridulatory mechanism. Science 190: 1309-1310.

1980. Vibration in Heteropoda venatoria (Sparassidae): A third method of sound production in spiders. J. Arachnol. 8: 193-200.

SPEChT, H. B., AND C. D. Dondale.

1960. Spider populations in New Jersey apple orchards. J. Econ. Ent. 53: 810-814.

TietJen, W. J., AND J. S. Rovner.

1980. Trail-following behaviour in two species of wolf spiders: sensory and etho-ecological concomitants. Anim. Behav. 28: 735-741.

Warren, L. O., W. B. Peck, and M. Tadic.

1967. Spiders associated with the fall webworm, Hyphantria cunea (Lepidoptera: Arctiidae). J. Kansas Ent. Soc. 40: 382-395. 

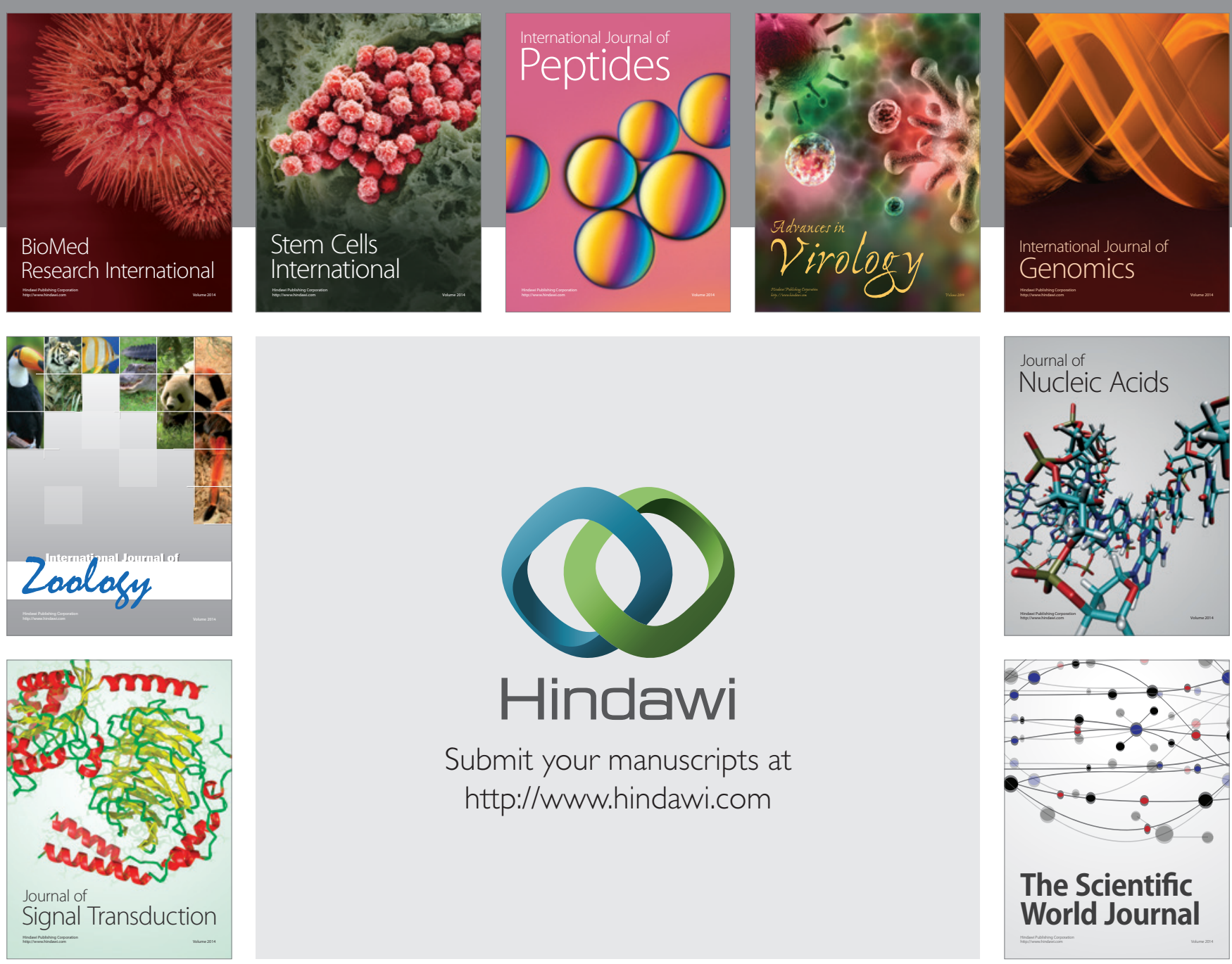

Submit your manuscripts at

http://www.hindawi.com
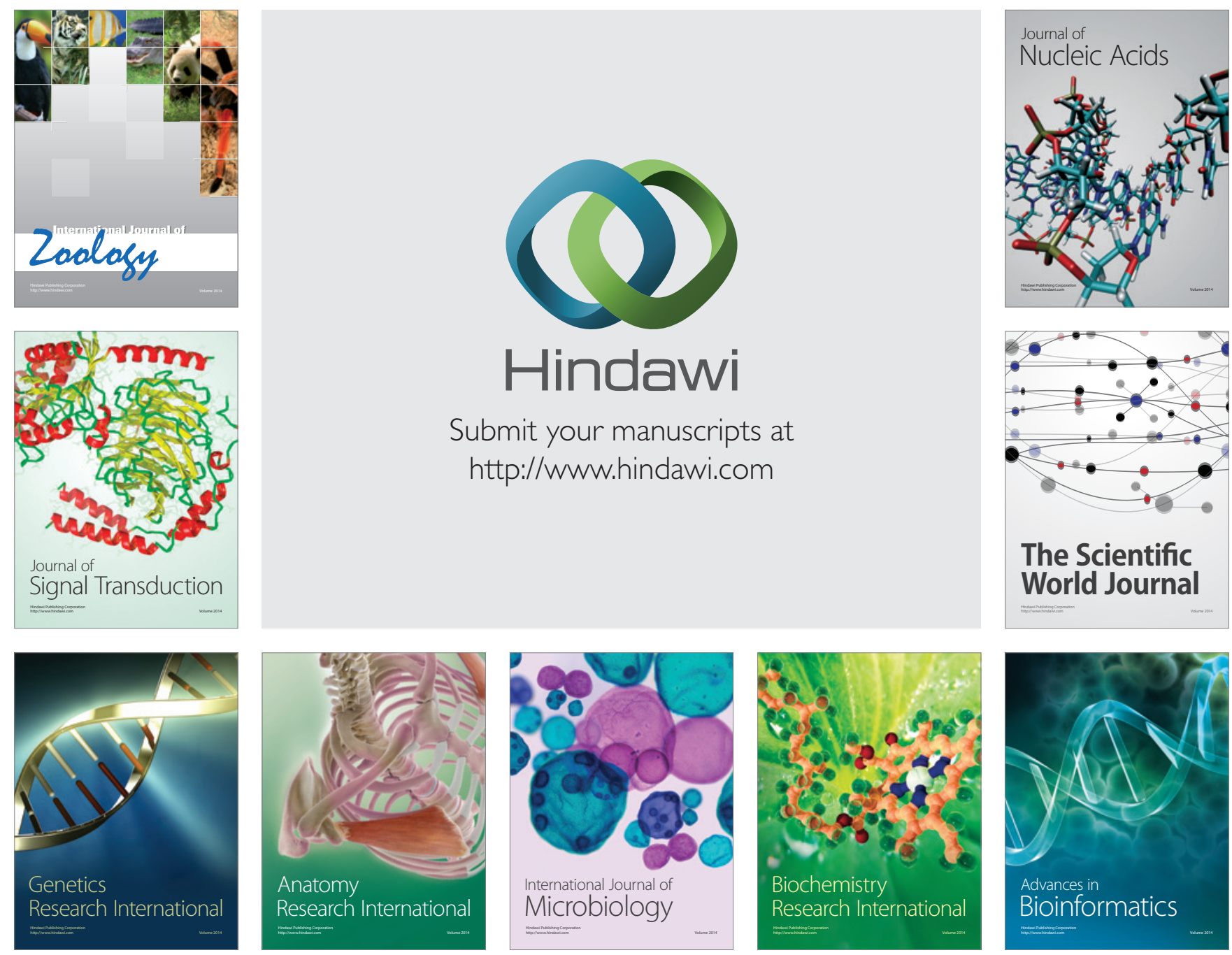

The Scientific World Journal
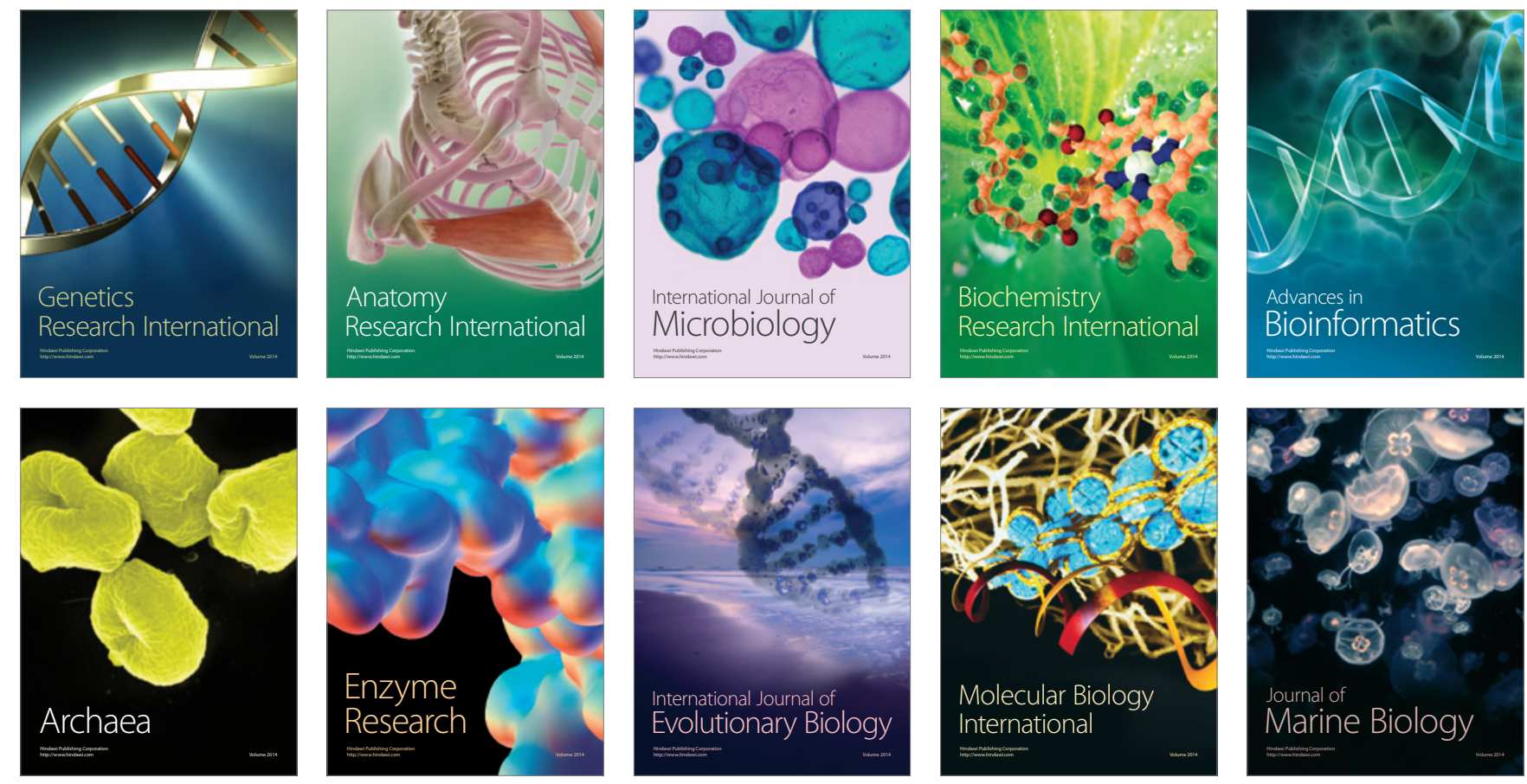